\title{
Ultrasonication Technique: A Method for Dispersing Nanoclay in Wood Adhesives
}

\author{
Alireza Kaboorani, Bernard Riedl, and Pierre Blanchet \\ Département des Sciences du Bois et de la Forêt, Faculté de Foresterie, de Géographie et de Géomatique, Université Laval, \\ 2425 Rue de la Terrasse, QC, Canada G1V 0A6 \\ Correspondence should be addressed to Bernard Riedl; bernard.riedl@sbf.ulaval.ca
}

Received 7 May 2013; Revised 19 July 2013; Accepted 1 August 2013

Academic Editor: Gaurav Mago

Copyright (C) 2013 Alireza Kaboorani et al. This is an open access article distributed under the Creative Commons Attribution License, which permits unrestricted use, distribution, and reproduction in any medium, provided the original work is properly cited.

\begin{abstract}
The efficiency of ultrasonication technique to disperse nanoclay in polyvinyl acetate (PVA) was examined. A hydrophilic nanoclay was added to PVA, and its effects on bond strength of wood joints were determined. The results of bond strength measured on block shear tests showed that nanoclay increased the bond strength of wood joints, especially in humid conditions. Atomic force microscopy (AFM) proved that it can be used to examine the quality of nanoclay dispersion in a matrix very precisely. The results of this study showed that ultrasonication technique is efficient in mixing nanoclay with the PVA matrix.
\end{abstract}

\section{Introduction}

Adhesives are among some of the most widely used components in structural materials due to the wide range of formulations that can be realized, providing a range of properties under conditions that other joining techniques cannot offer. Commercialization of wood adhesives in the mid 1950s generated a momentum for wood industries to diversify their products and enter into wider markets. Construction field was one of the markets which became more accessible to wood industries. Using adhesives allowed the manufacturers to fabricate wood composites with different sizes and shapes for the construction while maximizing resource utilization.

The price of wood adhesives covers an important part of production cost of wood products. As like any other industries, wood industries wish to bring down production costs in order to maximize profits. One of the means to cut the cost is to use low-cost adhesives in fabrication of the products. Low-cost adhesives usually have inferior properties. One of the examples of low-cost adhesives is polyvinyl acetate (PVA) which has been traditionally used for furniture assembly. As a wood adhesive, PVA has many advantages: nontoxic, with low negative impact on the environment, easy to use, and with low volatile organic compounds (VOCs) emissions. However,
PVA has low performance towards water ingress and high temperatures as well as low creep resistance. The vulnerability stems from the fact that PVA is a linear amorphous polymer with weak polar interaction among the molecular chains, which results in a relatively low glass-transition temperature $\left(T_{g}\right)$, near $28^{\circ} \mathrm{C}$.

Low-cost and simplicity of the application of PVA have convinced some wood products manufacturers to use PVA as an adhesive in the production of wood components for structures, despite the fact that PVA is not a heat-resistant adhesive. Using PVA as a structural adhesive puts the safety of home owners and fire fighters at risk as there is a higher probability of creep and sudden collapse of wood structures at high temperatures. In the past research, water resistance of PVA was mostly addressed, and little work has been done about heat resistance of PVA. Researchers have proposed some solutions to improve the properties of PVA. The solutions can be divided to two groups: (1) copolymerizing PVA with more hydrophobic or functional monomers [1-3] and (2) blending PVA with other adhesives or hardeners [4$11]$.

Introduction of nanotechnology has opened a new opportunity to develop new generation of adhesives with properties that cannot be gained by conventional methods. The 
incorporation of nanoparticles into a polymer matrix can lead to a simultaneous improvement of different material properties [12, 13]. The development of nanoparticles-reinforced adhesive materials is presently one of the most explored areas in materials science and engineering. The exceptional properties of nanoparticles have led to widespread research in this area. Nanofillers provide many advantages over classical microreinforcements for adhesive materials; for example, they allow thin bond lines and consequently lower the risk of embrittlement within the bulk adhesive material, resulting in improved adhesive tensile strength [14].

Nanocomposites, with dispersed nanoparticles, have been studied extensively due to their capability to improve mechanical, physical, thermal, and barrier properties with very low nanoparticles loading of $1-5 \mathrm{wt} \%$ [15-17]. For such composites, montmorillonite (MMT) and other clay nanoparticles have been used by many researchers [18-25]. With a structure of stacked platelets and one dimension of the platelet in the nanometer scale, MMT has a high aspect ratio and specific surface when exfoliated. If the platelets are dispersed properly, its nanosize can provide a significant amount of interface between the clay and the matrix resin with only a small weight percentage of MMT, thus contributing to the excellent mechanical and physical properties of the nanocomposites.

Exfoliating the layered structure of the MMT within a given matrix is crucial to improving the properties of a polymer. Usually dispersing the layered structure of the MMT is a challenge. Nanocomposite formation involves the migration or diffusion of the polymer into the interlayer galleries of the layered silicate which push apart or swell the silicate layers. There are some techniques to disperse MMT into polymers. For thermosetting polymer, mechanical mixing is the most common of the techniques to disperse MMT to a matrix, while heating is excluded. Mechanical technique includes several methods such as mechanical mixing, shear mixing, and ultrasonic mixing.

Ultrasonic irradiation, as a new technology, has been widely used in chemical reactions. When ultrasonic waves pass through a liquid medium, a large number of microbubbles form, grow, and collapse in very short times, about a few microseconds. Ultrasonication generates alternating lowpressure and high-pressure waves in liquids, leading to the formation and violent collapse of small vacuum bubbles. This phenomenon is termed cavitation and causes high-speed impinging liquid jets and strong hydrodynamic shear-forces. These effects are used for the deagglomeration of nanometersize materials. In this aspect, ultrasonication is an alternative to high-speed mixers and agitator bead mills. Ultrasonication has been used as a technique to disperse nanomaterials in different matrices [26-33].

In this study, ultrasonication was used to disperse the layered structures of MMT and develop MMT-reinforced PVA adhesives. Such reinforced adhesives can have improved properties. The main objective of this research is to study the feasibility of using ultrasonication as a technique to delaminate MMT layers and use delaminated, that is, exfoliated, MMT as nanoreinforcing filler for PVA. The bond strength of joints glued with newly formulated adhesives was examined under different conditions. Also structures of MMT/PVA composites (film) were evaluated as well.

\section{Experimental}

2.1. Materials. A commercial polyvinyl acetate (PVA) was received in liquid form. Nanoclay which is low-cost and the most widely studied nanofiller was used as nanofiller in this study. A hydrophilic nanoclay, namely, Lit. G-105 (polymergrade (PG) montmorillonite) was supplied by Nanocor, Inc., Arlington Heights, IL, USA. The specific gravity and cation-exchange capacity (CEC) of the nanoclay were 2.6 and 145 (meq/100 g), respectively. This commercial brand of nanoclay was chosen as nanoparticles because the past experience [34] has shown that dispersing this type of nanoclay by the high shear mixer in PVA is difficult and did not result in good dispersion. Black spruce (Picea mariana) obtained from trees grown in Québec province was used as a substrate for wood joints.

2.2. Preparation of Nanoclay/PVA Nanocomposites. Dispersion of nanoclay was conducted by a high-intensity ultrasonic horn $(60 \mathrm{kHz}$, maximum amplitude $100 \mathrm{~nm}$ from tip to tip, Branson PG). One-gram nanoclay was added to 20 grams of water, and then the solution was ultrasonicated for 3-5 min. The temperature of the solution was kept below $50^{\circ} \mathrm{C}$ to ensure high temperatures due to ultrasonication does not interfere with the results. To maintain the temperature of the mixture below $50^{\circ} \mathrm{C}$, the vessel with the mixture was cooled by means of recirculating ethylene glycol bath. Sonication experiments were carried out with $50 \%$ amplitude and a volume of $20 \mathrm{~mL}$ of the nanoparticle-water mixture. During ultrasonication, the sonication power was gradually raised while maintaining the temperature of the mixture below $50^{\circ} \mathrm{C}$. A certain amount of the ultrasonicated solution was added to PVA, depending on the percentage of nanoclay in PVA. Percentage of nanoclay in PVA (ranging from $0 \%$ to $4 \%)$ was based on solid mass of PVA. The mixtures of PVA with nanoclay were mixed for $30 \mathrm{~min}$. For X-ray diffraction (XRD), vapor sorption test, atomic force microscopy (AFM), and transmission electron microscopy (TEM), samples of nanocomposites were prepared by casting the PVA/nanoclay composites on Teflon sheets. Prior to further analyses, the sheets of nanocomposites were allowed to dry at room temperature for two weeks.

2.3. Fabrications and Tests of Wood Joints. Mixed solutions of PVA and nanoclay were used to bond wood samples. A wood species, black spruce, was used as substrate. Prior to gluing, the moisture content of wood was fixed at $12 \%$ by conditioning wood to $20^{\circ} \mathrm{C}$ and $60 \%$ relative humidity for two months. After applying glue on the surface of wood, the samples were pressed in an MTS hydraulic test machine with $50 \mathrm{kN}$ capacity at $2.46 \mathrm{~kg} / \mathrm{cm}^{2}$ pressure for two hours. Before testing, glued samples were conditioned to $20^{\circ} \mathrm{C}$ and $60 \%$ relative humidity $(\mathrm{RH})$ for two weeks. Twenty samples were tested for each set of formulation. 
To evaluate the impact of nanoclay on performance of wood joints, the shear strength of wood joints was measured in dry and wet states, and at an elevated temperature. An MTS hydraulic test machine with $50 \mathrm{kN}$ capacity was used for load application, and the data were acquired by a computer. Wood failure and maximum load were recorded for each test. Bond strength of adhesive in dry-state was studied on wood joints made of black spruce. The block shear tests were carried out according to ASTM D905-98. The sizes of samples for "wet-state" tests were the same as those for dry-state tests. For "wet-state" tests, the samples were taken directly out of the water after being immersed in water for 24 hours. Before the tests, excess water was wiped off from the samples. During the water immersion period, temperature of water was maintained at $23 \pm 1^{\circ} \mathrm{C}$.

Block shear tests at the elevated temperature were carried out according to ASTM 7247-07. Samples made of black spruce were heated in an oven, having a temperature controller with an integral and derivative (PID) control algorithm, until the temperature in the middle of samples reached $100^{\circ} \mathrm{C}$. On average, it took $30 \mathrm{~min}$ to reach $100^{\circ} \mathrm{C}$ in the middle of samples. After reaching $100^{\circ} \mathrm{C}$ in the middle of samples, the samples were kept at $100^{\circ} \mathrm{C}$ for $15 \mathrm{~min}$ more, followed by immediate block shear tests. The shear strength of samples was measured by an MTS hydraulic test machine.

\subsection{Characterization of the Nanoclay/PVA Nanocomposites}

2.4.1. Water-Vapor Sorption Analysis. One of main drawbacks of PVA as a wood adhesive is its vulnerability towards water and high humidity. PVA has low resistance towards water because of two reasons. First reason is the formation of hydrophilic hydroxyl and carboxyl groups during emulsion polymerization. PVA is usually partially hydrolyzed at the polymer branches to form hydrophilic hydroxyl and carboxyl groups appended to the polymer backbone. Second reason for the poor water resistance is the microscopic pores and water-soluble surfactant molecules which remain in the film allowing water-vapor to penetrate into the adhesive film easily [7]. Any decrease in water-vapor absorption of PVA by adding nanoclay results in more durable PVA adhesives. In order to find out the effect of adding nanoclay on response of nanoclay/PVA composites to humid environment, films of pure PVA and its composites were exposed to various humidity levels, and weight gain was monitored. The vapor sorption measurements were carried out at $25^{\circ} \mathrm{C}$ with a VTISA symmetrical vapor sorption analyzer, TA Instruments. The vapor sorption test was conducted in several steps. Between 7 and $10 \mathrm{mg}$ of sample was placed in the chamber. First, the samples dried at $0 \%$ humidity and $25^{\circ} \mathrm{C}$. As the sample weight equilibrated, the sample was exposed to $60 \%$, $70 \%, 80 \%, 90 \%$, and $95 \% \mathrm{RH}$, in a stepwise fashion, as the sample reached its maximum weight in each humidity level. Overall, the process took about $20 \mathrm{hrs}$.

2.4.2. X-Ray Diffraction (XRD). Small-angle X-ray scattering was used to examine efficiency of the ultrasonication technique to increase the distance between the nanoclay platelets. XRD experiments were conducted by an X-ray diffractometer (Siemens/Bruker) $(40 \mathrm{kV}, 40 \mathrm{~mA})$ using $\mathrm{Cu}(\lambda$ $=1.5406 \AA$ ) as the radiation source. The instrument consists of a Kristalloflex 760 generator, a 3-circle goniometer, and a Hi-Star area detector, and it was equipped with GADDS software. To measure the distance between nanoclay platelets before blending with PVA (powder form), the nanoclay powder was inserted in thin-walled $(0.01 \mathrm{~mm})$ glass capillary tubes $(1.0 \mathrm{~mm}$ diameter). Increasing interlayer spacing is identified by a shift of the diffraction peak to lower angles, according to Bragg's law $(n \lambda=2 d \sin \theta)$, leading eventually to featureless patterns (exfoliated structures).

2.4.3. Transmission Electron Microscopy (TEM). Transmission electron microscopy (TEM) allows a qualitative understanding of the internal structure, spatial distribution and dispersion of the nanoparticles within the polymer matrix, and views of the defect structure through direct visualization. Analyses were performed on a JEOL JEM-1230, transmission electron microscope at $80 \mathrm{kV}$. TEM specimens, having 50-70 $\mathrm{nm}$ thickness, were prepared by ultramicrotoming the nanocomposite samples encapsulated in an epoxy matrix.

2.4.4. Atomic Force Microscopy (AFM). Atomic force microscopy (AFM) observations were carried out using a NanoScope IIIa, an atomic force microscope (Veeco Instruments, Inc.). AFM measurements were done under ambient air conditions in tapping mode. The sensitivity of the tip deviation and the scanner resolution was $0.1 \mathrm{~nm}$. The resolution was set to 512 lines by 512 pixels for all observations. Two topographic and phase images were obtained within each sample for scan areas of $10 \mu \mathrm{m} \times 10 \mu \mathrm{m}$ and $50 \mu \mathrm{m} \times 50 \mu \mathrm{m}$. Surface roughness was calculated in $50 \mu \mathrm{m} \times 50 \mu \mathrm{m}$ scan areas, using the classical mean surface roughness parameters $R_{a}$ and $R_{q}$ (RMS). The parameters were calculated by the Nanoscope 5.30r3sr3 software as follows:

$$
\begin{gathered}
R_{a}=\frac{1}{n} \sum_{i=1}^{n}\left|Z_{i}-Z_{\text {ave }}\right|, \\
R_{q}=\mathrm{RMS}=\sqrt{\frac{\sum\left(Z_{i}-Z_{\mathrm{ave}}\right)^{2}}{n}},
\end{gathered}
$$

where $R_{a}$ is the mean roughness, the arithmetic average of the absolute values of the surface height deviations, and $R_{q}$ is the root mean square of the height, and in both equations $Z_{i}$ is the current $Z$ value, $Z_{\text {ave }}$ is the average of the $Z$ values within the given area, and $n$ is the number of points within the given area.

2.5. Statistical Analyses. A one-way analysis of variance model was used to study the effect of nanoclay content on shear strength of wood joints. The general linear model (GLM) procedure of the SAS program was used, and pairwise comparisons were then made using the protected Fisher LSD (least significant difference). 


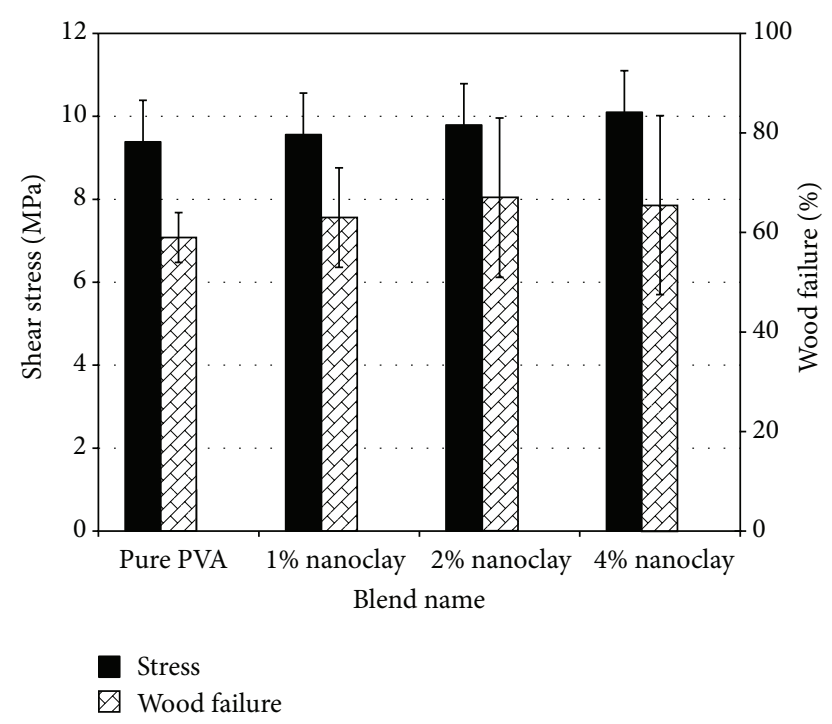

FIgURE 1: Bond strength for PVA and its nanocomposites in drystate at room temperature. Twenty samples were tested for each data point.

TABLE 1: Tabular summary of wood joints tests at various conditions*.

\begin{tabular}{lcccc}
\hline Samples & Pure PVA & $\begin{array}{c}\text { PVA and 1\% } \\
\text { nanoclay }\end{array}$ & $\begin{array}{c}\text { PVA and 2\% } \\
\text { nanoclay }\end{array}$ & $\begin{array}{c}\text { PVA and 4\% } \\
\text { nanoclay }\end{array}$ \\
\hline Dry & 9.38 & 10.06 & 10.77 & 10.91 \\
& $(8 \%)$ & $(5 \%)$ & $(8 \%)$ & $(8 \%)$ \\
\hline \multirow{2}{*}{ Wet } & 2.82 & 4.62 & 5.22 & 5.28 \\
& $(20 \%)$ & $(12 \%)$ & $(10 \%)$ & $(10 \%)$ \\
\hline The elevated & 1.33 & 2.60 & 2.76 & 2.52 \\
temperature & $(26 \%)$ & $(14 \%)$ & $(22 \%)$ & $(19 \%)$ \\
\hline
\end{tabular}

${ }^{*}$ The values given in the brackets are coefficient variations (\%).

\section{Results}

3.1. Bond Strength. Results of measuring shear strength of wood joints in dry tests are shown in Figure 1 and Table 1. Although fluctuations caused by varying loading of nanoclay on bond strength were not found significant, all joints with nanoclay in their formulations had improved shear strength. The increase in wood joints strength was between $2 \%$ and $7 \%$. The strength of joints showed improvements as nanoclay content increased in the matrix. An increase in bond strength of wood joints could be measured not only in terms of shear strength but also in terms of wood failure under shear load. Inclusion of nanoclay to PVA increased wood failure of wood joints under shear load (Figure 1). Higher wood failure in joints having nanoclay in their adhesives means that nanoclay increased the strength of glue line to a level that the strength of glue line surpassed the strength of wood. It has been reported that nanoclay improves the mechanical properties of polymers by optimizing the number of available reinforcing elements for carrying an applied load and deflecting cracks. Also the coupling between the tremendous surface area of the clay and the polymer matrix facilitates stress transfer to

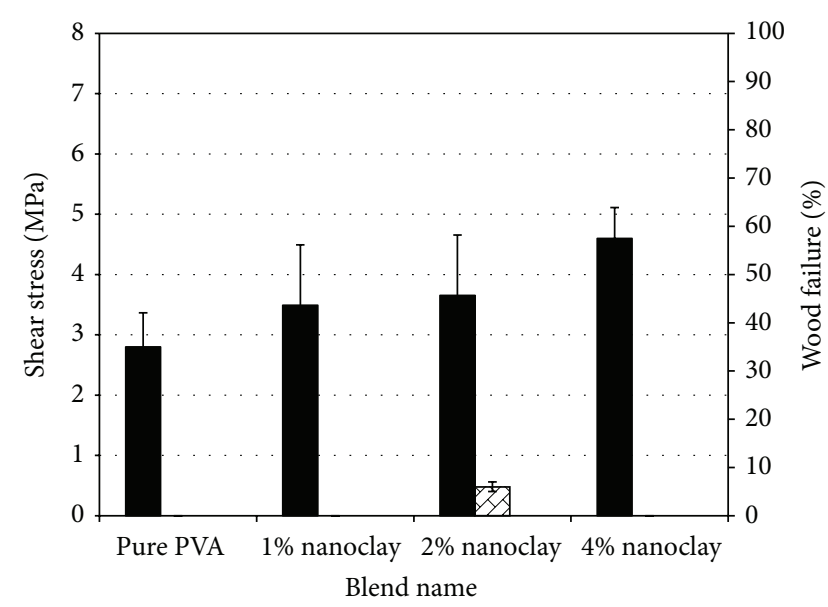

Stress

$\triangle$ Wood failure

Figure 2: Shear strength of wood joints bonded by PVA and its nanocomposites after 24-hour water exposure. Twenty samples were tested for each data point.

the reinforcement phase, allowing for mechanical property improvements [35-39].

Figure 2 and Table 1 give the values of shear strength after 24-hour exposure of wood joints to water. Water exposure decreased the shear strength of wood joints. The shear strength of joints made of pure PVA decreased drastically, dropping down to one-sixth of dry-state. Adding nanoclay to PVA improved the resistance of glue line towards water. The extent of improvement was between $25 \%$ and $64 \%$. Any increase in nanoclay loading in the matrix gave a boost to water resistance of wood joints (at all levels of loading). Positive effects of nanoclay on water resistance can be attributed to better barrier properties of glue line.

Past research shows that nanomaterials can improve the barrier properties of polymers [40-48]. The better barrier properties are associated to the fact that permeate molecules are forced to follow tortuous pathways, reducing the diffusion coefficients $[39,40]$. In addition, the inclusion of nanoclay with layered structures and their adhesion to the polymer generate additional free volume, more likely affecting the polymeric chains located near interfacial regions [45-47]. Wood failure of joints was affected by adding nanoclay as well. Wood joints bonded with PVA and $2 \%$ nanoclay showed small percentage of wood failure under the shear load. The wood failure could be related to good dispersion of nanoclay in PVA matrix.

Values of shear strength of wood joints at $100^{\circ} \mathrm{C}$ are given in Figure 3 and Table 1. Nanoclay had a positive effect on heat resistance of wood joints. The effects were more pronounced at 1\% loading (resulting in 96\% increase in shear strength at $100^{\circ} \mathrm{C}$ ). As nanoclay content in the PVA matrix increased, shear strength of wood joints improved at the elevated temperature. The extent of improvement was very significant at $4 \%$ nanoclay loading. The PVA with $4 \%$ nanoclay had 1.40 times higher shear strength. In our past 


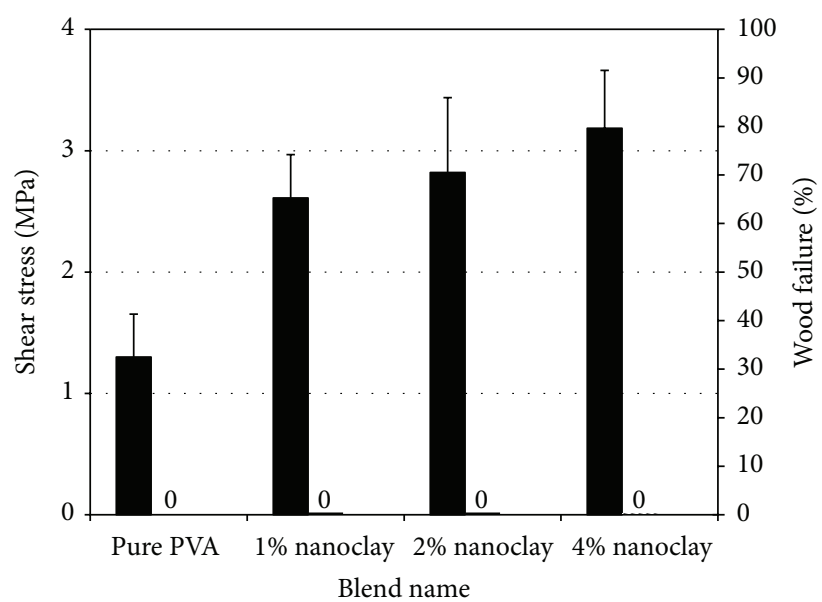

Stress

Ð Wood failure

FIGURE 3: Shear strength of wood joints at the elevated temperature $\left(100^{\circ} \mathrm{C}\right)$. Twenty samples were tested for each data point.

experience [34] with a high shear mixer, a decrease in shear strength of wood occurred at $4 \%$ nanoclay loading because of poor dispersion of nanoclay in the PVA matrix. Such a reduction did not occur in this study where an ultrasonic technique was used to disperse nanoclay particles in PVA. Thus, the results showed that using ultrasonic technique to disperse nanoclay particles in the matrix can enhance the effectiveness of nanoclay particles in the matrix.

Confinement of polymer chains in nanoclay galleries, restricting the mobility of polymer chains, and the ability of nanostructure materials to redistribute the deforming action over the volume of the materials have prominent impacts on improving the bond strength at high temperatures [49-51]. No wood failure was observed in the joints at the elevated temperature.

3.2. Water-Vapor Sorption. Results of vapor sorption tests are given in Figure 4. The negative values of vapor sorption at the beginning of the tests were related to the fact that the samples lost weight as they were conditioned at $0 \% \mathrm{RH}$ in the first step of the tests. Such a conditioning continued until the mass loss of samples leveled off. The same procedure was applied to other RH levels. The final values of vapor sorption at $95 \%$ $\mathrm{RH}$ in which the samples reached saturation points were used to compare the samples performance in the vapor sorption tests. As nanoclay was introduced to the formulation, values of vapor sorption decreased. The extent of decrease in vapor sorption was proportional to nanoclay loading, as the lowest value of vapor sorption was observed at a formulation with $4 \%$ nanoclay. The results of vapor sorption tests can explain the water resistance of nanoclay/PVA composites when used a wood adhesive.

3.3. X-Ray Diffraction (XRD). Generally, the crystalline structure of nanoparticles has typically been established using X-ray diffraction (XRD) analysis and transmission

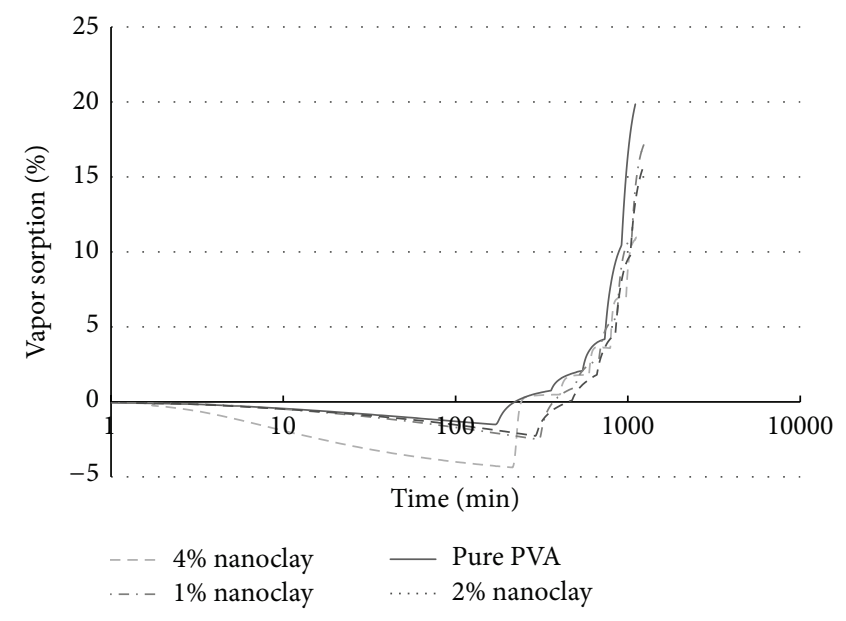

FIGURE 4: Vapor sorption of PVA/nanoclay composite film at different RH levels.

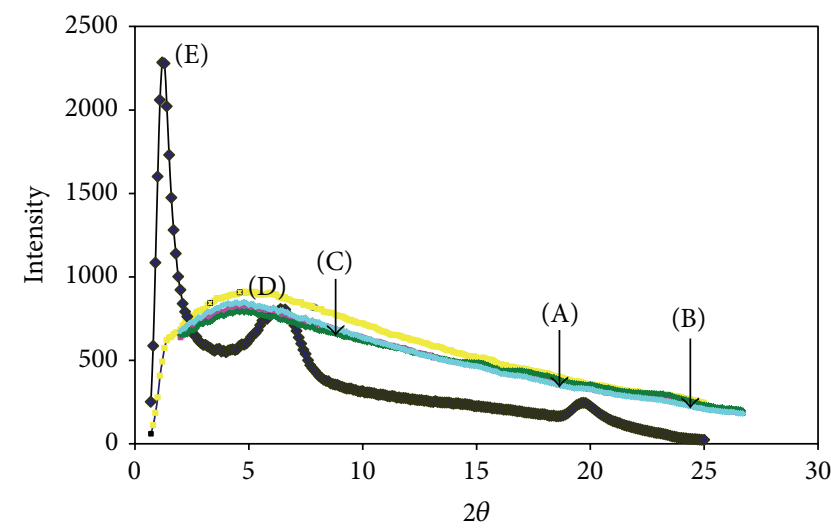
(A) Nanoclay (1\%)
(D) Pure PVA
(B) Nanoclay $(2 \%)$
(E) Pure nanoclay
(C) Nanoclay $(4 \%)$

FIGURE 5: X-ray diffraction (XRD) patterns of pure PVA, pure nanoclay, and their nanocomposites.

electron microscopy (TEM). Due to its relative easiness and availability, XRD is most commonly used to probe the nanocomposite structure and occasionally to study the kinetics of the polymer melt intercalation. XRD is used to probe alterations in the order of silicates by monitoring the position, shape, and intensity of their basal reflections. For an intercalated structure, the $\left(\begin{array}{lll}0 & 0 & 1\end{array}\right)$ characteristic peak tends to shift to lower-angle regime due to the expansion of the basal spacing. Although the layer spacing increases, there still exists an attractive force between the silicate layers to stack them in an ordered structure. In contrast, no peaks are observed in the XRD pattern of exfoliated polymer nanocomposites due to loss of the structural registry of the layers.

Figure 5 presents the X-ray diffraction profiles of pure PVA, pure nanoclay, and their nanocomposites prepared at different nanoclay loadings. Bragg's equation was used to calculate basal spacings of nanoclay from the XRD peak position. Nanoclay in pure forms had two peaks at $1.2^{\circ}$ and 
$6.7^{\circ}$. The intensity of peak at $1.2^{\circ}$ is higher than the other. According to Bragg's equation, the distances between clay platelets were $7.36 \mathrm{~nm}$ and $1.32 \mathrm{~nm}$. After mixing nanoclay with PVA at different loadings, both peaks disappeared. In fact, X-ray diffraction profiles of PVA nanocomposites with different amounts of nanoclay are like those of pure PVA. According to the definition of exfoliated structure, exfoliation is achieved when the individual montmorillonite platelets no longer exhibit an XRD deflection; it can be concluded that an exfoliated structure was achieved in all studied cases. It should be noted that it is very hard to draw any conclusion on structures of nanocomposites solely according to the results of XRD as some layered silicates initially do not exhibit well-defined basal reflections. Thus, peak broadening and intensity decreases are very difficult to study systematically. Therefore, conclusions concerning the mechanism of nanocomposites formation and their structure based solely on XRD patterns are only tentative. On the other hand, TEM allows a qualitative understanding of the internal structure, spatial distribution and dispersion of the nanoparticles within the polymer matrix, and views of the defect structure through direct visualization.

3.4. Transmission Electron Microscopy (TEM). Figure 6 shows the TEM images for nanocomposites containing nanoclay. Adding nanoclay at $1 \%$ and $2 \%$ loadings led to good dispersion of nanoclay in matrix. The distance between nanoclay platelets was increased, and the polymer chains entered between the platelets space. This nanostructure is referred to as exfoliated structure, giving superior properties to nanocomposites. As can be seen in Figure 6(c), nanocomposite with $4 \%$ is composed mostly of intercalated structure with very large aggregates or tactoids in the order of several tens of silicate layers. Intercalated structure is not considered an ideal structure for a nanocomposite, and it does not grant the nanocomposites with superior properties as exfoliated structure does. As observed in measuring bond strength (in dry condition and at the elevated temperature), adding nanoclay at $1 \%$ and $2 \%$ loadings gave a significant boost to the properties, but improvement of the properties at $4 \%$ content was not much different than with nanocomposites with $1 \%$ and $2 \%$ nanoclays. This phenomenon should be related to difficulty of dispersing nanoclay in matrix at high loadings.

Past research has shown that there is a direct linkage between properties of nanocomposites and quality of nanoclay dispersion [52-57]. In fact, the extent of improvement, as result of adding nanoclay, cannot be solely proportional to nanoclay loading because of difficulty in obtaining good dispersion at high loading.

3.5. Atomic Force Microscopy (AFM). Although XRD and TEM are used to study the quality of nanoclay dispersion in the polymer, problems involving XRD measurements (for example, some layered silicates initially do not exhibit welldefined basal reflections) and subjectivity of TEM observations raise some questions regarding the results obtained by XRD and TEM. In order to draw a firm conclusion on structure of nanocomposites, a quantitative technique should

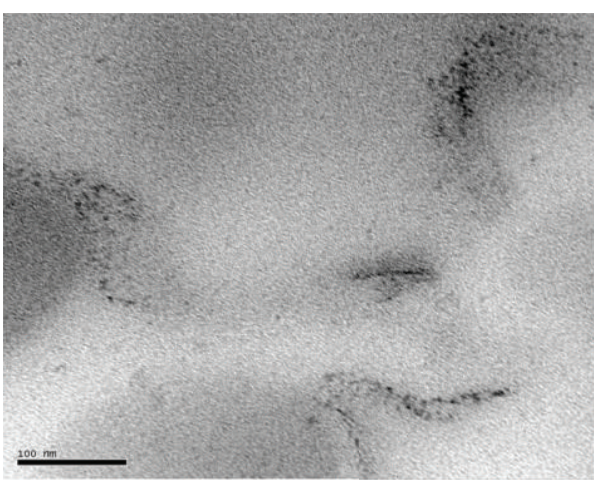

(a)

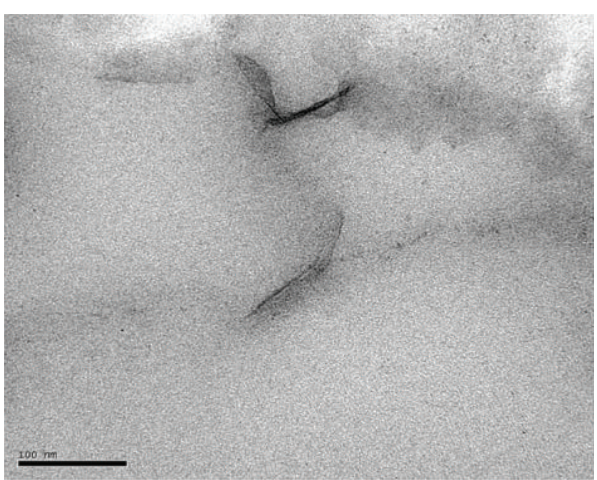

(b)

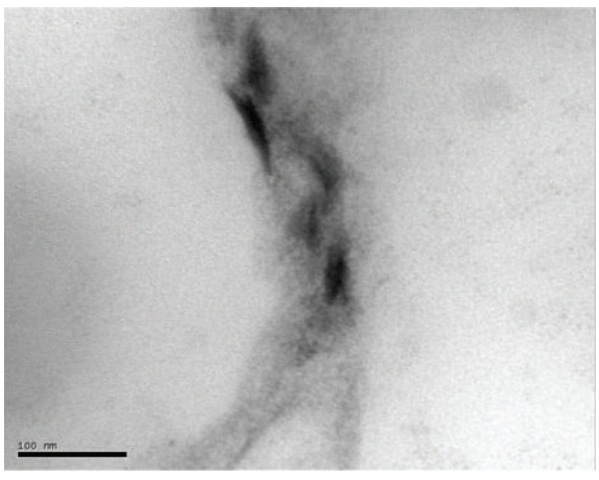

(c)

FIGURE 6: Images of PVA/nanoclay composites with different nanoclay loadings ((a) $1 \%$, (b) $2 \%$, and (c) $4 \%$ ). Scale bar is $100 \mathrm{~nm}$.

be used. In this study, atomic force microscopy (AFM) was used to determine the effects of adding nanoclay on PVA surface structure. The AFM images for pure PVA and its composites are presented in Figure 7. Pure PVA had a smooth surface as it had low roughness values. As nanoclay was added to the matrix, a reorganized surface was observed. The reorganization became more notable as nanoclay loading in the matrix increased. At $4 \%$ nanoclay loading, the surface of PVA film totally reorganized as a big increase in roughness values was detected although this roughness is still too small to be detected by human eye or resulted in light diffusion.

The results of this study show that the ultrasonication technique is an effective way to disperse nanoclay in the 


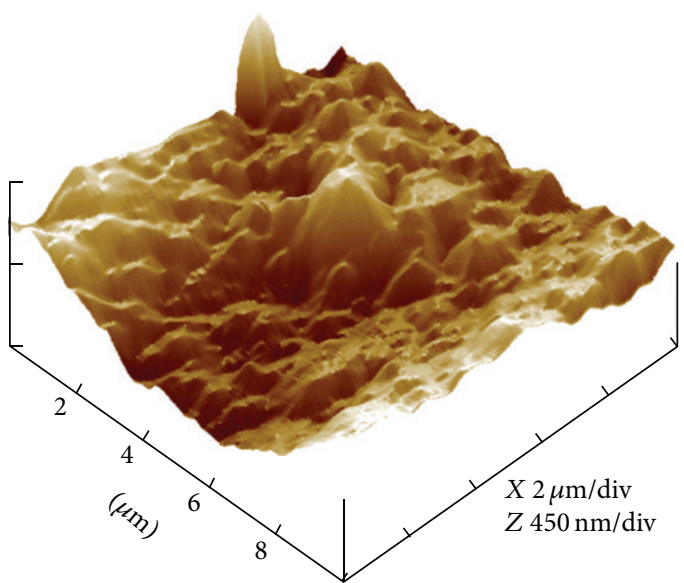

(a)

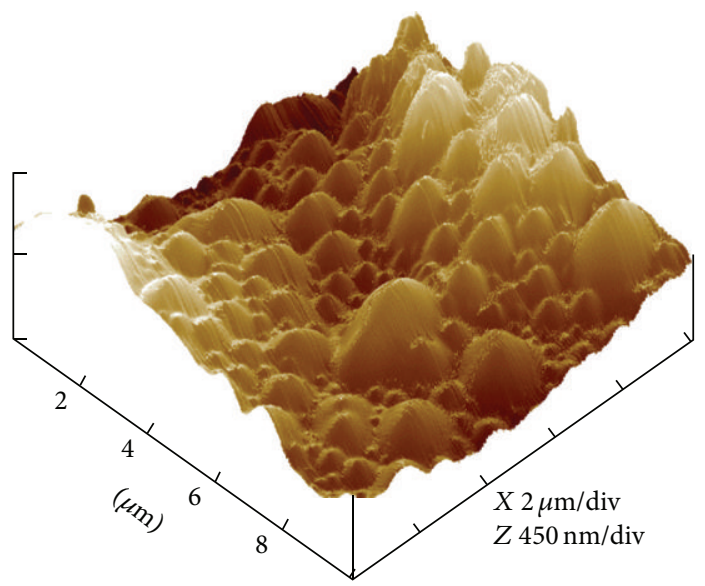

(c)

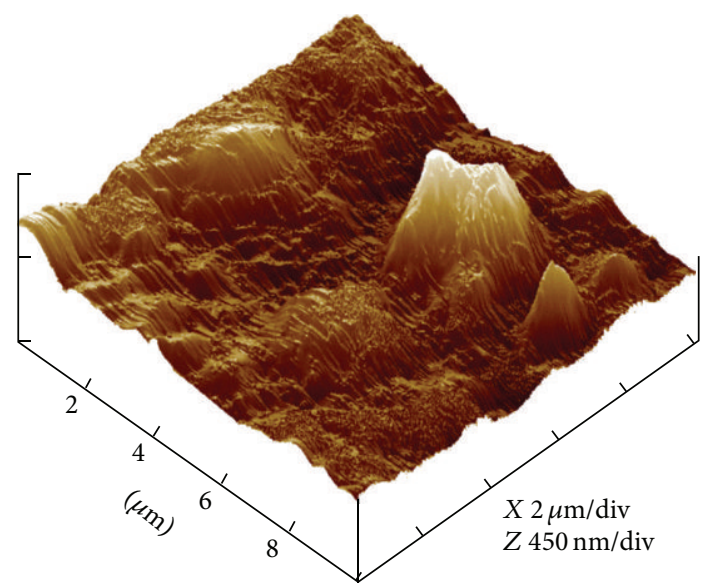

(b)

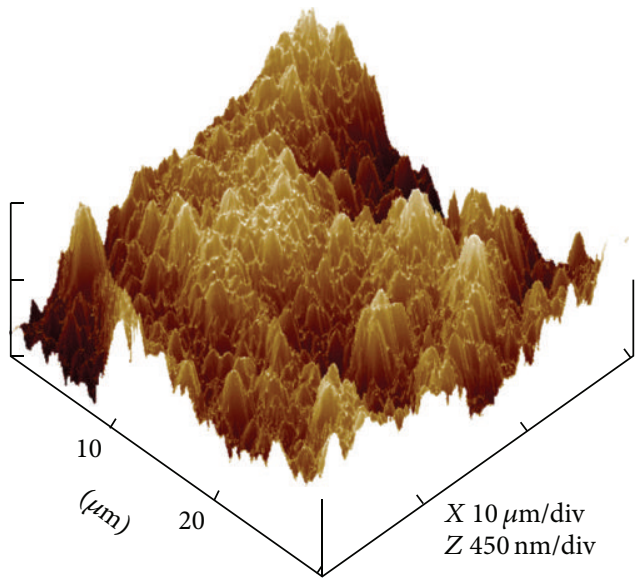

(d)

FIGURE 7: AFM images of pure PVA and its composites with different nanoclay loadings: (a) pure PVA, (b) $1 \%$ nanoclay, (c) $2 \%$ nanoclay, and (d) $4 \%$ nanoclay.

PVA matrix. The extent of improvement on PVA performance as a wood adhesive was superior or at least similar to that obtained by high-speed mixing [34]. When a high-speed mixer was used to disperse nanoclay at a high loading $(4 \%)$ in the matrix, a remarkable reduction was observed in the improvement gained by adding nanoclay. Such a reduction was not observed in the case of ultrasonic technique. Although adding 4\% nanoclay to the PVA matrix resulted in an intercalated structure, nanoclay did increase the shear strength of wood joints in humid conditions and at the elevated temperature. The results show that ultrasonic technique is very efficient in dispersing nanoclay especially at high loadings, contrary to the high shear speed mixer. Highspeed mixing could disperse nanoclay in the PVA only at low loadings and increased bond strength of PVA in different conditions. High-speed mixing has some disadvantages: possible damage to PVA emulsion (because of strong shear force used during the mixing), high cost, and high energy consumption. By contrast, ultrasonication technique has minimum negative impact on PVA emulsion. Moreover, ultrasonication technique is economical as ultrasonic mixing could take place before production of PVA and the solution containing nanoclay can be added to PVA during the production process. By considering the results obtained from this paper and our previous work [34] and by considering the advantages of ultrasonication technique over high-speed mixing, adding nanoclay to PVA in an industrial scale seems feasible and can be recommended to wood adhesive manufacturers.

\section{Conclusions}

The results of this study showed that ultrasonication technique is efficient in dispersing nanoclay in PVA at low $(1 \%$ and $2 \%$ ) and high (4\%) loadings. Bond strength of newly formulated adhesives measured on block shear samples increased in wet conditions and at the elevated temperature. In drystate, the positive effects of nanoclay on strength of glue line could be observed in terms of wood failure percentage. The strength of glue line was so high that some failure occurred in wood rather than in glue line. Improved barrier properties strengthened the resistance of glue line towards water, and subsequently significant increase was observed in bond strength in the wet-state. Contrary to the results obtained from dry condition, the extent of improvement 
on bond strength in wet-state was proportional to nanoclay loading. Bond strength of PVA at the elevated temperature was also affected by adding nanoclay. As nanoclay loading in the PVA matrix increased, the shear strength of wood joints at the elevated temperature improved, despite the fact that the biggest gain in the shear strength was observed at $1 \%$ nanoclay loading. Vapor sorption tests displayed that nanoclay reduced vapor sorption of the matrix, explaining higher water resistance of glue line having nanoclay in their formulations. The morphological studies of nanocomposites revealed that the fluctuations observed in bond strength tests were related to dispersion quality of nanoclay in the matrix (PVA). AFM proved that it is a credible technique to examine the quality of dispersion as the results of AFM fully conformed to the TEM observations. At low loadings (1\% and $2 \%$ ), an exfoliated structure is achieved, causing a significant improvement on PVA properties. At high loading (4\%), a coexistence of exfoliation and intercalation was observed, and so improvements on the shear strength of wood joints were achieved to a lesser extent.

\section{Acknowledgments}

The authors acknowledge the financial support from Natural Sciences and Engineering Research Council of Canada. Thanks are also extended to FPInnovations for their assistance.

\section{References}

[1] H. Zhou, "Research on the improvement of water resistance of polyvinyl acetate emulsion," Nianjie, vol. 12 , no. 4, pp. 11-12, 1991.

[2] Y. Cai, "Synthesis of melamine-formaldehyde resin modified poly (VAc-MMA) emulsion," China Adhesives, vol. 6, no. 2, pp. 43-45, 1997.

[3] Y. Chen, "Researches of wood adhesives with high strength, water and creep resistance," Nianjie, vol. 17, no. 1, pp. 25-27, 1996.

[4] G. Lu, "Improvement of polyvinyl acetate emulsions," Huagong Shikan, vol. 10, no. 6, p. 17, 1996.

[5] J. Comyn, Adhesion Science, The Royal Society of Chemistry, London, UK, 1997.

[6] J. Wang, "Study on improving properties of polyvinyl acetate emulsion," Zhanjie, vol. 20, no. 3, pp. 16-19, 1999.

[7] L. Qiao, A. J. Easteal, C. J. Bolt, P. K. Coveny, and R. A. Franich, "Improvement of the water resistance of poly(vinyl acetate) emulsion wood adhesive," Pigment and Resin Technology, vol. 29, no. 3, pp. 152-158, 2000.

[8] M. Huang, S. Kuo, H. Wu, F. Chang, and S. Fang, "Miscibility and hydrogen bonding in blends of poly(vinyl acetate) with phenolic resin," Polymer, vol. 43, no. 8, pp. 2479-2487, 2002.

[9] F. López-Suevos and C. E. Frazier, "Fracture cleavage analysis of PVAc latex adhesives: influence of phenolic additives," Holzforschung, vol. 60, no. 3, pp. 313-317, 2006.

[10] S. Kim and H. Kim, "Thermal stability and viscoelastic properties of MF/PVAc hybrid resins on the adhesion for engineered flooring in under heating system; ONDOL," Thermochimica Acta, vol. 444, no. 2, pp. 134-140, 2006.
[11] S. Kim and H. Kim, "Effect of addition of polyvinyl acetate to melamine-formaldehyde resin on the adhesion and formaldehyde emission in engineered flooring," International Journal of Adhesion and Adhesives, vol. 25, no. 5, pp. 456-461, 2005.

[12] B. Wetzel, F. Haupert, and M. Q. Zhang, "Epoxy nanocomposites with high mechanical and tribological performance," Composites Science and Technology, vol. 63, no. 14, pp. 20552067, 2003.

[13] J. Cho, M. S. Joshi, and C. T. Sun, "Effect of inclusion size on mechanical properties of polymeric composites with micro and nano particles," Composites Science and Technology, vol. 66, no. 13, pp. 1941-1952, 2006.

[14] O. Jacobs, W. Xu, B. Schädel, and W. Wu, "Wear behaviour of carbon nanotube reinforced epoxy resin composites," Tribology Letters, vol. 23, no. 1, pp. 65-75, 2006.

[15] X. L. Ji, J. E. Hampsey, Q. Y. Hu, J. B. He, Z. Z. Yang, and Y. F. Lu, "Mesoporous silica-reinforced polymer nanocomposites," Chemistry of Materials, vol. 15, no. 19, pp. 3656-3662, 2003.

[16] Q. Zhang and L. A. Archer, "Optical polarimetry and mechanical rheometry of poly(ethylene oxide) - silica dispersions," Macromolecules, vol. 37, no. 5, pp. 1928-1936, 2004.

[17] B. J. Ash, R. W. Siegel, and L. S. Schadler, "Mechanical behavior of alumina/poly(methyl methacrylate) nanocomposites," Macromolecules, vol. 37, no. 4, pp. 1358-1369, 2004.

[18] A. Pegoretti, J. Kolarik, C. Peroni, and C. Migliaresi, "Recycled poly(ethylene terephthalate)/layered silicate nanocomposites: morphology and tensile mechanical properties," Polymer, vol. 45, no. 8, pp. 2751-2759, 2004.

[19] K. M. Lee and C. D. Han, "Linear dynamic viscoelastic properties of functionalized block copolymer/organoclay nanocomposites," Macromolecules, vol. 36, no. 3, pp. 804-815, 2003.

[20] J. H. Chang, B. S. Seo, and D. H. Hwang, "An exfoliation of organoclay in thermotropic liquid crystalline polyester nanocomposites," Polymer, vol. 43, no. 10, pp. 2969-2974, 2002.

[21] J. Ma, P. Xiang, Y. W. Mai, and L. Q. Zhang, "A novel approach to high performance elastomer by using clay," Macromolecular Rapid Communications, vol. 25, no. 19, pp. 1692-1696, 2004.

[22] T. D. Fornes and D. R. Paul, "Structure and properties of nanocomposites based on nylon-11 and -12 compared with those based on nylon-6," Macromolecules, vol. 37, no. 20, pp. 76987709, 2004.

[23] F. Bensadoun, N. Kchit, C. Billotte, F. Trochu, and E. Ruiz, "A comparative study of dispersion techniques for nanocomposite made with nanoclays and an unsaturated polyester resin," Journal of Nanomaterials, vol. 2011, Article ID 406087, 12 pages, 2011.

[24] J. W. Gilman, T. Kashiwagi, and J. D. Lichtenhan, "Nanocomposites: a revolutionary new flame retardant approach," SAMPE Journal, vol. 33, no. 4, pp. 40-46, 1997.

[25] B. M. Le, C. Wilkie, S. Bourbigot, and S. Duquesne, Fire Retardancy of Polymers: The Use of Micro- and Nano-Sized Mineral Fillers, R.S.C., Cambridge, UK, 2004.

[26] S. D. Burnside and E. P. Giannelis, "Synthesis and properties of new poly(dimethylsiloxane) nanocomposites," Chemistry of Materials, vol. 7, no. 9, pp. 1597-1600, 1995.

[27] S. S. Park, N. Bernet, S. de la Roche, and H. T. Hahn, "Processing of iron oxide-epoxy vinyl ester nanocomposites," Journal of Composite Materials, vol. 37, no. 5, pp. 465-476, 2003.

[28] R. D. West and V. M. Malhotra, "Rupture of nanoparticle agglomerates and formulation of $\mathrm{Al}_{2} \mathrm{O}_{3}$-epoxy nanocomposites using ultrasonic cavitation approach: effects on the structural 
and mechanical properties," Polymer Engineering and Science, vol. 46, no. 4, pp. 426-430, 2006.

[29] H. Mahfuz, M. F. Uddin, V. K. Rangari, M. C. Saha, S. Zainuddin, and S. Jeelani, "High strain rate response of sandwich composites with nanophased cores," Applied Composite Materials, vol. 12, no. 3-4, pp. 193-211, 2005.

[30] H. Xia and Q. Wang, "Preparation of conductive polyaniline/nanosilica particle composites through ultrasonic irradiation," Journal of Applied Polymer Science, vol. 87, no. 11, pp. 18111817, 2003.

[31] A. Yasmin, J. J. Luo, and I. M. Daniel, "Processing of expanded graphite reinforced polymer nanocomposites," Composites Science and Technology, vol. 66, no. 9, pp. 1182-1189, 2006.

[32] B. Bittmann, F. Haupert, and A. K. Schlarb, "Ultrasonic dispersion of inorganic nanoparticles in epoxy resin," Ultrasonics Sonochemistry, vol. 16, no. 5, pp. 622-628, 2009.

[33] B. Bittmann, Ultraschalldispergierung von Anorganischen Nanopartikeln in Epoxidharz und Charakterisierung der Resultierenden Werkstoffe [Ph.D. thesis], Institut für Verbundwerkstoffe, Kaiserslautern, Germany, 2009.

[34] A. Kaboorani and B. Riedl, "Effects of adding nano-clay on performance of polyvinyl acetate (PVA) as a wood adhesive," Composites A, vol. 42, no. 8, pp. 1031-1039, 2011.

[35] E. P. Giannelis, "Polymer layered silicate nanocomposites," Advanced Materials, vol. 8, no. 1, pp. 29-35, 1996.

[36] M. Alexandre and P. Dubois, "Polymer-layered silicate nanocomposites: preparation, properties and uses of a new class of materials," Materials Science and Engineering R, vol. 28, no. 1, pp. 1-63, 2000.

[37] T. J. Pinnavaia and G. W. Beall, Polymer-Clay Nanocomposites, John Wiley \& Sons, New York, NY, USA, 2001.

[38] S. S. Ray and M. Okamoto, "Polymer/layered silicate nanocomposites: a review from preparation to processing," Progress in Polymer Science, vol. 28, no. 11, pp. 1539-1641, 2003.

[39] H. Fischer, "Polymer nanocomposites: from fundamental research to specific applications," Materials Science and Engineering C, vol. 23, no. 6-8, pp. 763-772, 2003.

[40] L. Nielsen, "Models for the permeability of filled polymer systems," Journal of Macromolecular Science A, vol. 1, no. 5, pp. 929-942, 1967.

[41] R. K. Bharadwaj, "Modeling the barrier properties of polymerlayered silicate nanocomposites," Macromolecules, vol. 34, no. 26, pp. 9189-9192, 2001.

[42] W. R. Falla, M. Mulski, and E. L. Cussler, "Estimating diffusion through flake-filled membranes," Journal of Membrane Science, vol. 119, no. 1, pp. 129-138, 1996.

[43] N. A. Plate and Y. P. Yampol'skii, "Relationship between structure and transport properties for high free volume polymeric materials," in Polymeric Gas Separation Membranes, D. R. Paul and Y. P. Yampol'skii, Eds., chapter 5, pp. 155-207, CRC Press, Boca Raton, Fla, USA, 1994.

[44] A. Thran, G. Kroll, and F. Faupel, "Correlation between fractional free volume and diffusivity of gas molecules in glassy polymers," Journal of Polymer Science B, vol. 37, no. 23, pp. 33443358, 1999.

[45] R. A. Pethrick, "Positron annihilation-a probe for nanoscale voids and free volume?" Progress in Polymer Science, vol. 22, no. 1, pp. 1-47, 1997.

[46] Y. Q. Wang, Y. P. Wu, H. F. Zhang, L. Q. Zhang, B. Wang, and Z. F. Wang, "Free volume of montmorillonite/styrene-butadiene rubber nanocomposites estimated by positron annihilation lifetime spectroscopy," Macromolecular Rapid Communications, vol. 25, no. 23, pp. 1973-1978, 2004.

[47] O. Becker, Y. B. Cheng, R. J. Varley, and G. P. Simon, "Layered silicate nanocomposites based on various high-functionality epoxy resins: the influence of cure temperature on morphology, mechanical properties, and free volume," Macromolecules, vol. 36, no. 5, pp. 1616-1625, 2003.

[48] P. Winberg, M. Eldrup, N. J. Pedersen, M. A. van Es, and F. H. J. Maurer, "Free volume sizes in intercalated polyamide 6/clay nanocomposites," Polymer, vol. 46, no. 19, pp. 8239-8249, 2005.

[49] A. Laachachi, E. Leroy, M. Cochez, M. Ferriol, and J. M. L. Cuesta, "Use of oxide nanoparticles and organoclays to improve thermal stability and fire retardancy of poly(methyl methacrylate)," Polymer Degradation and Stability, vol. 89, no. 2, pp. 344-352, 2005.

[50] F. Yang and G. L. Nelson, "Polymer/silica nanocomposites prepared via extrusion," Polymers for Advanced Technologies, vol. 17, no. 4, pp. 320-326, 2006.

[51] B. N. Dudkin, G. G. Zainullin, P. V. Krivoshapkin, E. F. Krivoshapkina, and M. A. Ryazanov, "Influence of nanoparticles and nanofibers of aluminum oxide on the properties of epoxy composites," Glass Physics and Chemistry, vol. 34, no. 2, pp. 187-191, 2008.

[52] T. G. Macia-Agullo, J. C. Fernindez-Garcia, A. Torro-Palau, A. C. Orgiles-Barcelo, and J. M. Martin-Martinez, "Addition of silica to polyurethane adhesives," Journal of Adhesives, vol. 38, no. 1-2, pp. 31-53, 1992.

[53] T. V. González, C. G. Salazar, J. R. de la Rosa, and V. González, "Nylon 6/organoclay nanocomposites by extrusion," Journal of Applied Polymer Science, vol. 108, no. 5, pp. 2923-2933, 2008.

[54] M. Mirzataheri, M. Atai, and A. R. Mahdavian, "Physical and mechanical properties of nanocomposite barrier film containing encapsulated nanoclay," Journal of Applied Polymer Science, vol. 118, no. 6, pp. 3284-3291, 2010.

[55] C. Zilg, R. Mülhaupt, and J. Finter, "Morphology and toughness/stiffness balance of nanocomposites based upon anhydride-cured epoxy resins and layered silicates," Macromolecular Chemistry and Physics, vol. 200, no. 3, pp. 661-670, 1999.

[56] A. Ranade, N. A. D'Souza, and B. Gnade, "Exfoliated and intercalated polyamide-imide nanocomposites with montmorillonite," Polymer, vol. 43, no. 13, pp. 3759-3766, 2002.

[57] X. Fu and S. Qutubuddin, "Polymer-clay nanocomposites: exfoliation of organophilic montmorillonite nanolayers in polystyrene," Polymer, vol. 42, no. 2, pp. 807-813, 2001. 

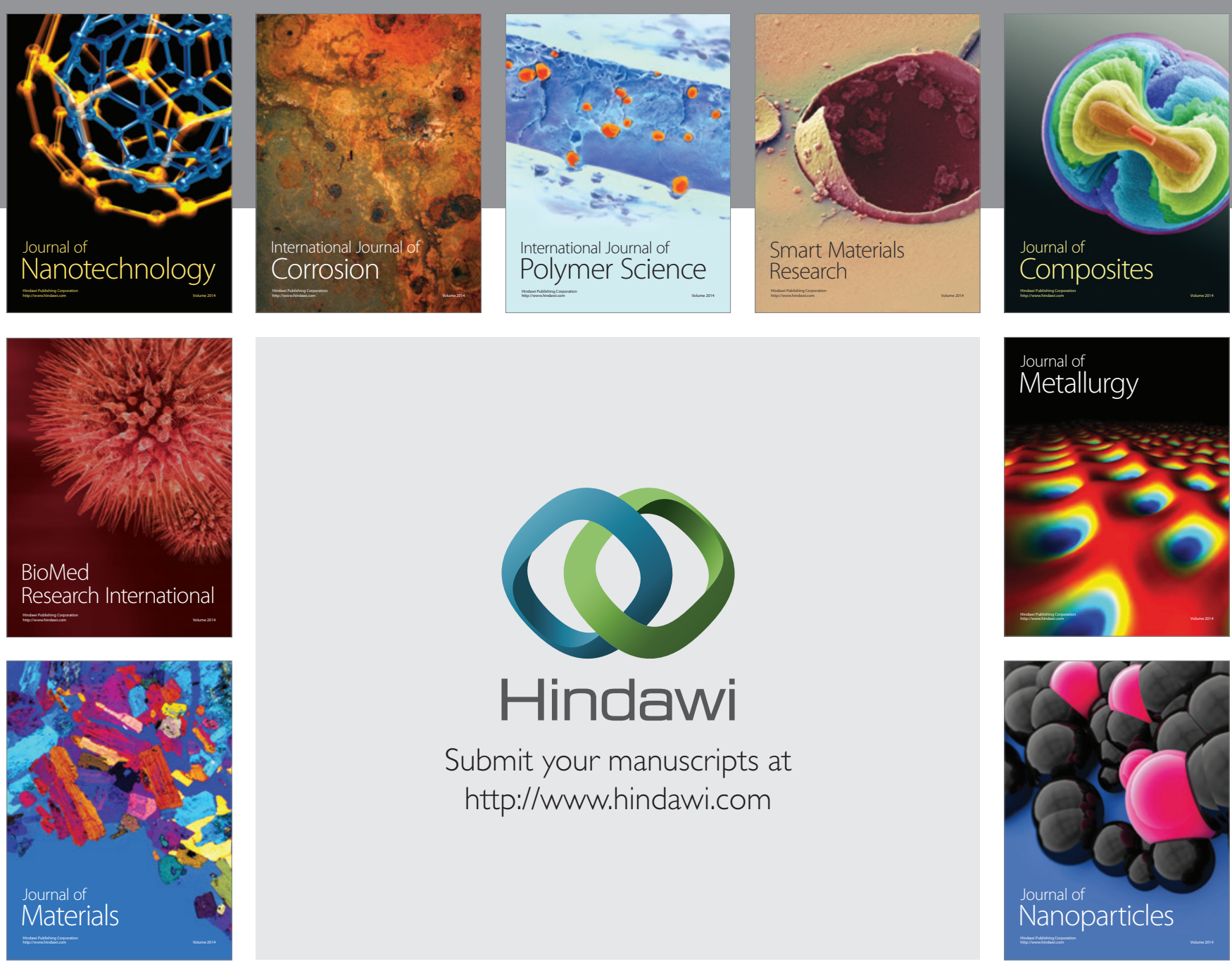

Submit your manuscripts at http://www.hindawi.com
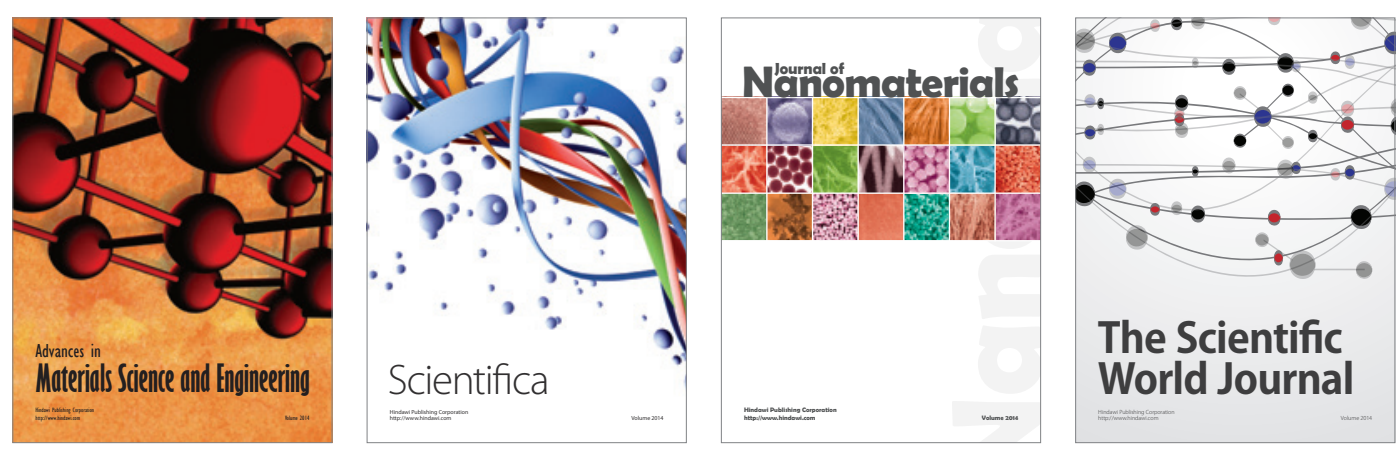

\section{The Scientific World Journal}
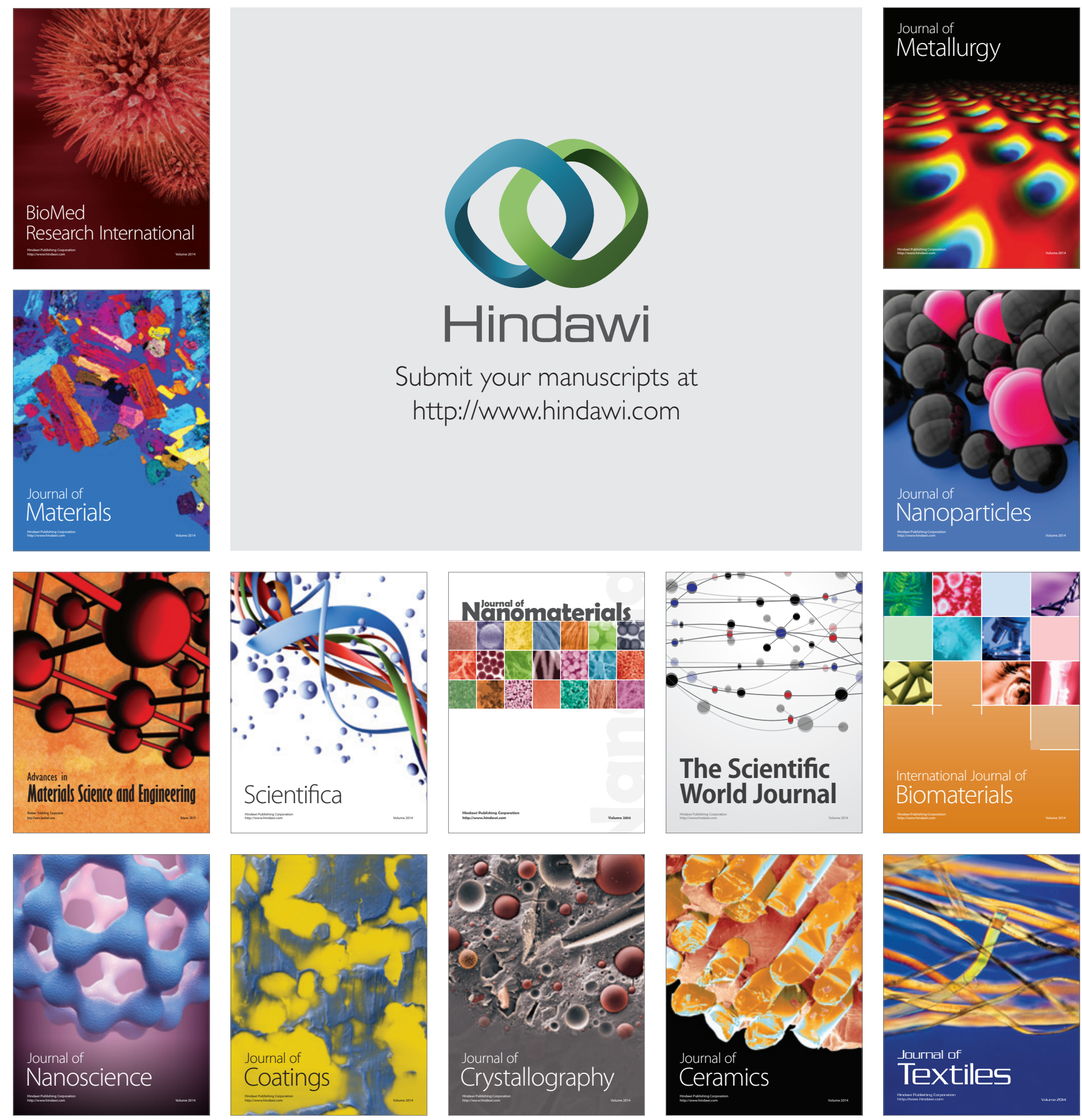